\begin{abstract}
Check for updates
Received 5th May 2020,

Accepted 19th June 2020

DOI: $10.1039 / \mathrm{dOfo} 01153 \mathrm{c}$

rsc.li/food-function
\end{abstract}

Cite this: Food Funct., 2020, 11, 5782

\section{Mānuka honey-derived methylglyoxal enhances microbial sensing by mucosal-associated invariant T cells $\dagger$}

\author{
Jeffry S. Tang, (iD $\ddagger^{a, b}$ Benjamin J. Compton, (id $\ddagger^{c}$ Andrew Marshall, \\ Regan Anderson, ${ }^{c}$ Yanyan Li, ${ }^{a, b}$ Hannah van der Woude, ${ }^{a}$ Ian F. Hermans, ${ }^{a}$ \\ Gavin F. Painter (D) ${ }^{c}$ and Olivier Gasser (D) *a,b
}

\begin{abstract}
Methylglyoxal (MGO) is the main antimicrobial determinant associated with using Mānuka Honey as a topical dressing. While direct mechanisms of Mānuka honey MGO's antimicrobial activity have been demonstrated, such as disruption of bacterial fimbria and flagella, no interaction of Mānuka honey-derived MGO with antimicrobial effector cells of the immune system, such as mucosalassociated invariant T cells (MAIT cells), has yet been reported. MAIT cells are an abundant subset of human $\mathrm{T}$ cells, critical for regulating a diverse range of immune functions, including antimicrobial defense mechanisms but also mucosal barrier integrity. MAIT cells become activated by recognition of an important microbial metabolite, 5-amino-6-D-ribitylaminouracil (5-A-RU), which is produced by a wide range of microbial pathogens and commensals. Recognition is afforded when 5-A-RU condenses with mammalian-cell derived MGO to form the potent MAIT cell activator, 5-(2-oxopropylideneamino)-6-D-ribitylaminouracil (5-OP-RU). Formation of 5-OP-RU and its subsequent presentation to MAIT cells by major histocompatibility (MHC)-related molecule 1 (MR1) facilitates host-pathogen and host-commensal interactions. While MGO is a metabolite naturally present in mammalian cells, it is unclear whether exogenous dietary MGO sources, such as those obtained from Mānuka honey intake, can contribute to 5-OP-RU formation and enhance MAIT cell activation. In this work, we report that endogenous $M G O$ is the rate-limiting substrate for converting microbial 5-A-RU to 5-OP-RU and that Mānuka honeyderived MGO significantly enhances MAIT cell activation in vitro. Our findings posit a novel mechanism by which intake of a food item, such as Mānuka honey, can potentially support immune homeostasis by enhancing MAIT cell-specific microbial sensing.
\end{abstract}

\footnotetext{
${ }^{a}$ Malaghan Institute of Medical Research, PO Box 7060, Wellington 6242, New Zealand.E-mail: ogasser@malaghan.org.nz

${ }^{b}$ High-value Nutrition National Science Challenge, Auckland 1010, New Zealand ${ }^{c}$ Ferrier Institute, Victoria University of Wellington, Wellington 6012, New Zealand $\dagger$ Electronic supplementary information (ESI) available. See DOI: 10.1039/ d0fo01153c

$\$$ These authors contributed equally to this work.
}

\section{Introduction}

Honey, a complex natural product generated by bees from the flower nectar of melliferous plants, has long been used as a wound dressing and is notable for its antimicrobial properties. ${ }^{1,2}$

Monofloral honey types derived from different flowering plants exhibit substantial differences in antimicrobial activities, when tested against various clinically-relevant microbial isolates. $^{1,2}$ This observation is often linked to differences in the chemical composition of active compounds found in different monofloral honey types. ${ }^{1}$

One monofloral honey type that exhibits a particularly broad spectrum of antimicrobial activity is Mānuka honey, ${ }^{1-3}$ derived from the flowers of the Mānuka bush (Leptospermum species). ${ }^{4}$ Unlike many honeys that contain hydrogen peroxide as a major antimicrobial component, the main antimicrobial determinant of Mānuka honey is methylglyoxal (MGO). ${ }^{5,6}$ This is an $\alpha$-dicarbonyl compound, formed from the spontaneous dehydration of dihydroxyacetone, which naturally occurs in the nectar of flowers of some species belonging to the Leptospermum genus, including Leptospermum scoparium, Leptospermum polygalifolium, and some related Leptospermum species native to New Zealand and Australia. ${ }^{7-9}$ While MGO is especially abundant in Mānuka honey, its occurrence in other honey types are limited, and if present, are typically found in lower amounts than that in Mānuka honey. ${ }^{1,10}$

While the direct mechanisms of antimicrobial activity of honey MGO have been reported, such as the ability to limit bacterial adherence and motility by disrupting the structure of fimbriae and flagella, ${ }^{11}$ to date, no studies have reported the ability of Mānuka honey MGO to enhance microbial sensing by cells of the immune system.

Mucosal-associated invariant $\mathrm{T}$ cells (MAIT cells) are a recently-described, abundant subset of $\mathrm{T}$ cells in humans, typically enriched in mucosal surfaces, such as the oral and gastrointestinal tracts. ${ }^{12}$ They are also abundant in peripheral blood and the liver. MAIT cells can protect the body from bacterial pathogens by the recognition of small molecule vitamin B2- 


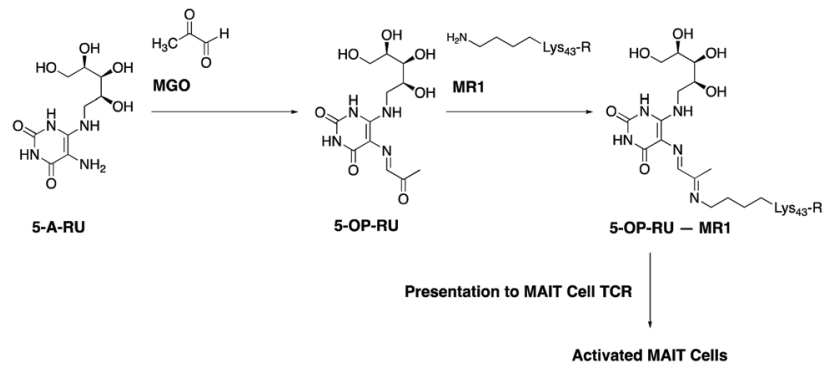

Fig. 1 Formation of 5-OP-RU, a potent activator of mucosal-associated invariant T cells (MAIT cells), from the condensation of microbial 5-A-RU with methylglyoxal. Once formed, 5-OP-RU can be subsequently presented to MAIT cells by major histocompatibility (MHC)-related molecule 1 (MR1). This activates MAIT cells and facilitates host-pathogen and host-commensal interactions. (Abbreviations: 5-A-RU, 5-amino-6-Dribitylaminouracil; MGO, methylglyoxal; 5-OP-RU, 5-(2-oxopropylideneamino)-6-D-ribitylaminouracil; MR1, major histocompatibility complex-related protein-1; 5-OP-RU - MR1, 5-OPRU covalentlybonded to MR1; TCR, T-cell receptor).

based metabolite intermediates produced through the riboflavin biosynthesis pathway, which is present in a wide range of bacteria, mycobacteria and yeasts. ${ }^{13-17}$ A most notable early intermediate in this pathway is 5-amino-6-D-ribitylaminouracil (5-A-RU). Recognition of 5-A-RU by MAIT cells is facilitated by formation of the potent MAIT cell activator, 5-(2-oxopropylideneamino)-6-D-ribitylaminouracil (5-OP-RU), ${ }^{18,19}$ through the non-enzymatic condensation of microbial 5-A-RU with endogenous MGO (Fig. 1). The latter metabolite (MGO) is naturally formed in mammalian cells by virtue of a combination of glycolysis, ketone body and threonine metabolisms. ${ }^{20}$ Once formed, 5-OP-RU can form a Schiff base with Lys43 of major histocompatibility complex (MHC)-related protein-1 (MR1), ${ }^{15,18}$ which is subsequently presented to the 'semi-invariant' $\alpha \beta \mathrm{T}$ cell receptor (TCR) expressed on MAIT cells (Fig. 1). This antigen presentation activates MAIT cells, leading to the production of a variety of cytokines, chemokines and responses that in turn protect the body against microbial infection. ${ }^{21,22}$

While MGO is an endogenous metabolite naturally present in mammalian cells, it is unclear whether exogenous dietary MGO sources, such as those obtained from Mānuka honey intake, can contribute to 5-OP-RU formation and enhance MAIT cell activation. In this communication, we report that endogenous MGO is the rate-limiting substrate for the conversion of microbial 5-A-RU to 5-OP-RU and that Mānuka honey-derived MGO significantly enhances MAIT cell activation in vitro in the presence of 5-A-RU. Our finding posits a novel mechanism by which Mānuka honey-derived MGO can contribute to the body's immune responses against microbial infection.

\section{Materials and methods}

\subsection{Synthesis of 5-amino-6-D-ribitylaminouracil (5-A-RU)}

5-A-RU was produced by synthetic methods based on a published procedure. ${ }^{23}$ In short, D-ribitylamine and 6-chlorouracil were heated to $170{ }^{\circ} \mathrm{C}$ in a sealed vessel with triethylamine for $45 \mathrm{~min}$ before purification on an ion-exchange resin (AG-1X8), which gave 6-(D-ribitylamino)uracil. 5-Nitrosylation was achieved by treating 6-(D-ribitylamino)uracil with $\mathrm{NaOH}$ and $\mathrm{NaNO}_{2}$ at $0{ }^{\circ} \mathrm{C}$ followed by the addition of aqueous acetic acid. Ion-exchange chromatography (AG-1X8) gave 5-nitroso-6-(Dribitylamino)uracil which, upon reduction with $\mathrm{Na}_{2} \mathrm{~S}_{2} \mathrm{O}_{4}$, afforded 5-A-RU which was used without further purification.

\subsection{Methylglyoxal analysis in Mānuka honey}

Mānuka Health Mānuka honey MGO ${ }^{\mathrm{TM}} 30+$ and MGO ${ }^{\mathrm{TM}} 400+$ produced by European honeybees (Apis mellifera) from the nectar of the native New Zealand Mānuka bush, Leptospermum scoparium were supplied by Mānuka Health New Zealand (grade $\mathrm{MGO}^{\mathrm{TM}} 30+$, batch FMH3710 with $72.6 \mathrm{mg} \mathrm{kg}^{-1}$ methylglyoxal, and grade MGOTM 400, batch FMH3563 with $451.4 \mathrm{mg}$ $\mathrm{kg}^{-1}$ methylglyoxal). This honey was tested for purity and quality and has a certified MGO content. ${ }^{24}$

\subsection{Characterisation of 5-(2-oxopropylideneamino)-6-D- ribitylaminouracil (5-OP-RU) by HPLC-MS and ${ }^{1}$ NMR analyses}

Formation of 5-OP-RU was obtained by reacting a solution of 5-A-RU (5 $\mathrm{mg} \mathrm{mL}^{-1}$ in DMSO) with methylglyoxal (2 equivalents) and monitoring the reaction by HPLC-MS (ESI Scheme $1 \dagger)$. After 30 min post mixing, analysis showed almost complete consumption of 5-A-RU and the formation of 5-OP-RU alongside a small amount of the less-active degradative species, $^{25}$ 7-methyl-8-D-ribityllumazine (RL-7-Me) (ESI Fig. $1 \dagger)$.

\subsection{Isolation and in vitro stimulation of human peripheral blood mononuclear cells (PBMC)}

Anticoagulated blood was obtained from healthy volunteers. The study was approved by the Victoria University of Wellington Human Ethics Committee (ref: 19966) and conducted in adherence to standard biosecurity and institutional safety procedures. Informed consent was obtained from all subjects. Peripheral blood mononuclear cells (PBMC) were isolated from blood by means of density gradient centrifugation using Leucosep tubes (Sigma, St Louis, MO). PBMC were resuspended in $10 \%(\mathrm{v} / \mathrm{v})$ DMSO in heat-inactivated $\left(56^{\circ} \mathrm{C}, 30 \mathrm{~min}\right)$ fetal bovine serum (ThermoFisher Scientific, Rockford, IL) and stored in liquid nitrogen until use.

PBMC were resuspended in an RPMI medium (ThermoFisher Scientific, Rockford, IL), supplemented with $10 \%$ heat-inactivated fetal bovine serum and plated in a 96-well round-bottom plate at a concentration of $2.5 \times 10^{6}$ cell per mL. Cells were treated with $5-\mathrm{A}-\mathrm{RU}^{26}$ in the presence or absence of equimolar amounts (0.5-1000 nM) of synthetic methylglyoxal (Sigma, St Louis, MO) or PBS dilutions of commercial Mānuka honey products $\mathrm{MGO}^{\mathrm{TM}} 30+(0.46 \mu \mathrm{g}$ honey per mL-1 mg honey per $\mathrm{mL})$ or $\mathrm{MGO}^{\mathrm{TM}} 400+(0.16 \mathrm{mg}$ honey per $\mathrm{mL}$ ). The admixtures of 5-A-RU and either synthetic or honey-derived MGO were prepared immediately prior to use. The PBMC cultures were treated at $37^{\circ} \mathrm{C}$ overnight before flow cytometric analysis. 


\subsection{Flow cytometry}

Samples were incubated with Zombie Aqua ${ }^{\mathrm{TM}}$ dye (BioLegend, San Diego, CA) for $15 \mathrm{~min}$ in the dark at room temperature, to distinguish live cells from the dead, and were subsequently washed with FACS buffer. Privigen normal immunoglobulin (CSL Behring, Bern, Switzerland) was used as an Fc-block in staining and wash buffers. Antibody staining was carried out for $20 \mathrm{~min}$ in the dark on ice. Antibodies were sourced from BioLegend unless otherwise mentioned. The following antibodies were used throughout: anti-CD3 (UCHT1), anti-CD161 (HP-3G10), anti-TCR V $\alpha 7.2$ (3C10), anti-CD137 (4B4-1).

Stained cells were measured using an LSR-II flow cytometer (BD, Heidelberg, Germany). Data were analysed with FlowJo 10 for Mac (Tree Star, Ashland, Ore).

\subsection{Statistical analysis}

All graphs and statistical tests were carried out using GraphPad Prism 8 (GraphPad, La Jolla, CA). Statistical significance was assessed using one-way ANOVA with Tukey post-tests or non-parametric Mann-Whitney $U$-tests.

\section{Results and discussion}

To verify that 5-OP-RU is the major species produced from the reaction of 5-A-RU and MGO, HPLC-MS and ${ }^{1} \mathrm{H}$ NMR analyses were conducted on the reaction mixture. The precursor, 5-A-RU, is unstable and can undergo degradative hydrolysis to the purported compound 5,5-dihydroxy-6-(D-ribitylamino)pyrimidine-2,4(3H,5H)-dione (5-D-RP) (ESI Scheme $1 \dagger) .^{23}$ The formation of this compound is evidenced by the forerunning peak $(T=0.68 \mathrm{~min})$ in the chromatogram of freshly synthesised 5-A-RU which corresponds to the chemical species with $m / z$ of 294.1 (ESI Fig. $1 A_{\dagger}^{\dagger}$ ).

When mixed with 2 equivalents of MGO in DMSO, 5-A-RU was converted into 5-OP-RU as a single major product $(\mathrm{m} / \mathrm{z}$ : 331.1, $T=5.23 \mathrm{~min}$ ) (ESI Fig. $1 \mathrm{~B} \dagger$ ). Further characterisation of the reaction mixture by ${ }^{1} \mathrm{H}$ NMR spectroscopy reveals a species with spectral fingerprint (ESI Fig. $2 \dagger$ ) matching that of the ${ }^{1} \mathrm{H}$ NMR spectrum of authentic 5-OP-RU previously reported. ${ }^{19} \mathrm{~A}$ minor species that was also formed in the reaction mixture was likely to be RL-7-Me. Eluting at $1.79 \mathrm{~min}$, this species has a $\mathrm{m} / \mathrm{z}$ of 313.1 and results from a spontaneous intramolecular condensation reaction between the ribitylamine and methyl ketone groups. ${ }^{19,23}$

In this study, we used a well-established flow cytometry method to identify and quantify activated MAIT cells in human peripheral blood mononuclear cells (PBMC). ${ }^{26}$ Specifically, MAIT cells were identified using a combination of antibodies specific for the three cell-surface markers CD3, TCR V 07.2 and CD161. CD137 was used as an activation specific marker, as it has been shown to be upregulated upon antigenspecific activation. $^{27}$ Thus, non-activated $v s$. activated MAIT cell were identified as $\mathrm{CD} 137^{-} \mathrm{CD} 161^{+} \mathrm{TCRV} \alpha 7.2^{+} \mathrm{T}$ cells $v s$. $\mathrm{CD} 137^{+} \mathrm{CD} 161^{+} \mathrm{TCRV} \alpha 7.2^{+} \mathrm{T}$ cells (Fig. 2A).
A

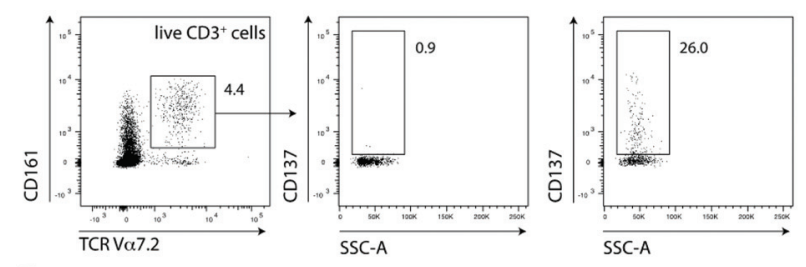

B

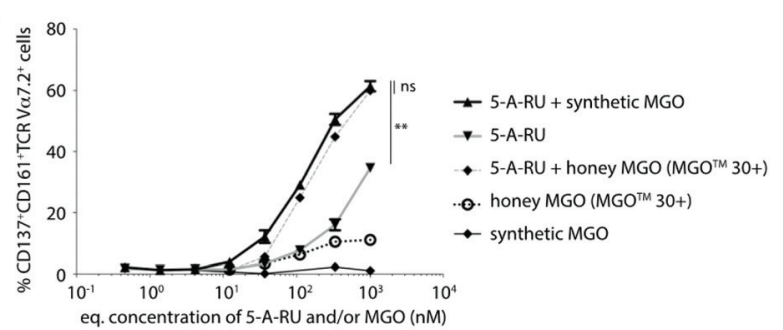

C

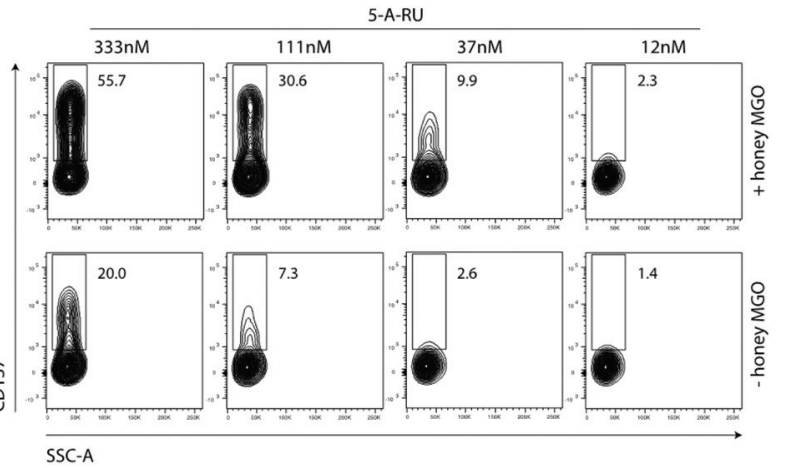

D

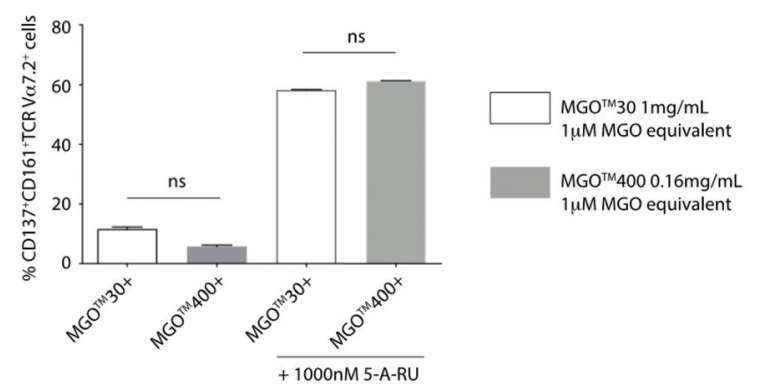

Fig. 2 Synthetic or Mānuka honey-derived methylglyoxal (MGO) enhances antigen-specific activation of mucosal-associated invariant $T$ cells (MAIT cells) in the presence of 5-amino-6-D-ribitylaminouracil (5-A-RU). (A) Representative gating and quantification of activated MAIT cells. (B) Dose-dependent activation of MAIT cells with 5-A-RU in the absence or presence of equimolar concentrations of synthetic or Mānuka-honey derived methylglyoxal. (C) Side-by-side comparison of 5-A-RU-mediated activation of MAIT cells in the presence (upper panels) or absence (lower panels) of Mānuka-honey derived MGO. (D) Impact of MGO-equivalent amounts of MGOTM $30+$ and MGOTM $400+$ Mānuka honeys on 5-A-RU-mediated activation of MAIT cells. Plots show mean \pm SEM. Data are representative of two independent experiments conducted using PBMC samples obtained from two donors (two independently-treated technical replicates/donor PBMC). Statistics were calculated using (B) one-way ANOVA with Tukey post-hoc tests using $1000 \mathrm{nM}$ data points throughout; or (D) using the non-parametric Mann-Whitney $U$-tests. ${ }^{* *} p<0.01$; ns, not significant. Only relevant statistics are shown. 
Using the gating and quantification strategy defined above, PBMC subjected to five different treatment regimens were independently analysed for the extent of activation of MAIT cells (Fig. 2B). It is clear, that in the absence of 5-A-RU, treating PBMC with synthetic MGO alone at any concentration (0.5-1000 nM) did not activate MAIT cells to any significant extent (Fig. 2B). This finding suggests that MGO is unlikely to bind MR1 nor activate MAIT cells.

When PBMC were treated with increasing concentrations (0.5-1000 nM) of 5-A-RU, there was a dose-dependent increase in the proportion of activated MAIT cells. While this observation gives the impression that 5-A-RU alone activates MAIT cells, it is well-established that 5-A-RU neither binds MR1 nor directly activates MAIT cells. ${ }^{28}$ Instead, 5-A-RU can diffuse into host mammalian cells and form simple adducts with a number of common host cellular metabolites that provide MR1-binding MAIT cell agonists ${ }^{26}$ including endogenous MGO and glyoxal, to form 5-OP-RU and 5-(2-oxoethylideneamino)-6-D-ribitylaminouracil (5-OE-RU) ${ }^{18}$ respectively. Glyoxal is an $\alpha$-dicarbonyl metabolite that can arise from glyceraldehyde via glycolaldehyde autoxidation. ${ }^{20}$ It is important to note that 5-OP-RU remains as one of the most potent agonists of MAIT cells, characterised to-date, and since this metabolite is absent in mammals, it therefore allows hostpathogen discrimination by the mammalian immune system. $^{12,22,29}$

When PBMC were treated with equimolar amounts of exogenously-added, synthetic MGO and 5-A-RU, there was consistently and significantly higher proportion of activated MAIT cells compared to those induced at all corresponding concentrations of 5-A-RU treatment alone (Fig. 2B and C). This finding suggests that exogenous MGO can enhance MAIT cell activation, demonstrating the presence of a bottleneck, ratelimiting conversion of 5-A-RU to MAIT cell agonists, in the absence of any exogenous MGO.

Using Mānuka honey with an MGO content of $72.6 \mathrm{mg} \mathrm{kg}^{-1}$ (MGO ${ }^{\mathrm{TM}} 30+$ Mānuka honey), we demonstrated that when PBMC were treated with various honey dilutions to give a final MGO concentration equimolar $(0.5-1000 \mathrm{nM})$ to that of 5-A-RU, a similar extent of activation of MAIT cells, in a manner consistent with activation by synthetic MGO and 5-A-RU (i.e. in situ formation of 5-OP-RU), was observed (Fig. 2B). There was clearly a higher proportion of activated MAIT cells in PBMC treated with increasingly higher equimolar concentrations of 5-A-RU and honey-derived MGO (Fig. 2C).

To confirm that MGO in the honey matrix was the component responsible for controlling the 5-A-RU-dependent activation of MAIT cells, Mānuka honey with $72.6 \mathrm{mg} \mathrm{kg}^{-1}$ MGO $\left(\right.$ MGO $^{\text {TM }} 30+$ Mānuka honey) was directly compared to Mānuka honey with $451.4 \mathrm{mg} \mathrm{kg}^{-1}$ MGO (MGOTM 400+ Mānuka honey). When both honeys were diluted so that each gave an equivalent final concentration of $1 \mu \mathrm{M} \mathrm{MGO}$, and PBMC independently incubated with equimolar $(1 \mu \mathrm{M}) 5-\mathrm{A}-\mathrm{RU}$, both treatments gave a similar extent of MAIT cell activation (Fig. 2D), suggesting that 5 -OP-RU, is the main component responsible for activating the MAIT cells.
These findings altogether demonstrate for the first time, that MGO in Mānuka honey could increase the conversion rate of 5-A-RU into 5-OP-RU. We hereby speculate that this effect is likely to enhance microbial sensing by the immune system through increased activation of peripheral MAIT cells; a speculation needing confirmation in future work.

Free 5-A-RU can be released by bacteria in quantities sufficient to conjugate with exogenously added metabolites that can subsequently bind MR1 and stimulate MAIT cells. ${ }^{18}$ 5-OP-RU, externally-administered to the body by cutaneous application or oral gavage, has been shown to cross mucosal barriers to reach peripheral organs, such as the thymus for presentation to resident MAIT cells. ${ }^{30}$ While the mechanism(s) of transport of 5-OP-RU across these barriers remain unknown, these findings clearly highlight a novel mechanism by which commensal bacteria in mucosal surfaces can 'remotely' contribute to the activation of MAIT cells in systemic sites. In line with the findings of these previous studies, ${ }^{18,30}$ it is plausible that methylgloxal-rich food, such as Mānuka honey, could contribute to the pool of 5-OP-RU at mucosal surfaces via condensation of Mānuka honey-derived MGO and microbial 5-A-RU from commensals. The pre-formed 5-OP-RU could then cross mucosal barriers to further enhance MAIT cell activation in systemic sites or potentially support local, gastrointestinal immune homeostasis through the stimulation of intraepithelial MAIT cells. ${ }^{31}$

Another interesting finding in this communication is that, there are clearly other compounds present in Mānuka honey that can activate MAIT cells, albeit only to a relatively limited extent. PBMC treated with $\mathrm{MGO}^{\mathrm{TM}} 30+$ Mānuka honey dilutions alone, in the absence of 5-A-RU, can activate MAIT cells, up to $c a$. $12 \%$ of gated MAIT cells (Fig. 2B and D). Given the plasticity of the antigen-binding cleft of the MR1 protein and its propensity to bind small aromatic, mono- and/or bicylic molecules ${ }^{29}$ it is not surprising to anticipate a variety of small molecules fitting the above chemical criteria, likely present in Mānuka honey, that may bind MR1 and activate MAIT cells. At present, we do not have an indication on the identity of these compounds.

Future work should aim to identify other potential MAIT cell agonists present in Mānuka honey. Particular emphasis should be put on whether they are of relevance to peripheral MAIT cell activation, as they will need to be demonstrated to cross mucosal sites and reach peripheral sites, like 5-OP-RU, before their potential effects can be conveyed under physiologically-relevant conditions.

\section{Conclusions}

In this communication, we report that Mānuka honey-derived MGO can increase the conversion rate of 5-A-RU to 5-OP-RU, which contributes to the activation of MAIT cells in peripheral blood. We showed that Mānuka honey, a prototypical food source rich in methylglyoxal, can dose-dependently activate MAIT cells in the presence of equimolar amounts of the 
microbial metabolite, 5-A-RU, in a manner consistent with activation by synthetic methylglyoxal and 5-A-RU. Based on our findings, we propose that Mānuka honey-derived MGO may play a role in enhancing microbial sensing by MAIT cells, which may in turn assist MAIT cells in controlling microbial infection and systemic immune homeostasis.

\section{Abbreviations}

$\begin{array}{ll}\text { 5-A-RU } & \text { 5-Amino-6-D-ribitylaminouracil } \\ \text { 5-OE-RU } & \text { 5-(2-Oxoethylideneamino)-6-D-ribitylaminouracil } \\ \text { 5-OP-RU } & \text { 5-(2-Oxopropylideneamino)-6-D-ribitylaminouracil } \\ \text { 5-D-RP } & \begin{array}{l}\text { 5,5-Dihydroxy-6-(D-ribitylamino)pyrimidine-2,4 } \\ (3 H, 5 H) \text {-dione }\end{array} \\ & \text { Mucosal-associated invariant T cells } \\ \text { MAIT } & \\ \text { cells } & \text { Methylglyoxal } \\ \text { MGO } & \text { Major histocompatibility complex } \\ \text { MHC } & \text { MHC-related protein-1 } \\ \text { MR1 } & \text { Peripheral blood mononuclear cells } \\ \text { PBMC } & \text { 7-Methyl-8-D-ribityllumazine } \\ \text { RL-7-Me } & \text { T-cell receptor } \\ \text { TCR } & \end{array}$

\section{Author contributions}

JT reviewed the data and wrote the manuscript, $\mathrm{BC}$ provided experimental design and contributed to writing of the manuscript, RA, AM, IH and GFP contributed reagents, contributed to research design and writing of the manuscript. OG performed experiments (with contributions from JT, YL and HvdW), provided experimental design, reviewed the data and co-wrote the manuscript.

\section{Conflicts of interest}

There are no conflicts to declare.

\section{Acknowledgements}

We are grateful to the staff of the Hugh Green Cytometry Core at the Malaghan Institute of Medical Research for expert support with flow cytometry and all colleagues at the Malaghan Institute for insightful discussion and advice. We thank Mānuka Health New Zealand who kindly donated the Mānuka honey products tested. This work was financially supported by the New Zealand Ministry of Business Innovation and Employment (RTVU1603), the New Zealand Health Research Council (HRC 14/502), and the New Zealand HighValue Nutrition National Science Challenge. We would also like to acknowledge Dr Alissa Cait for her input into the design of this article's graphical abstract.

\section{References}

1 D. A. Carter, S. E. Blair, N. N. Cokcetin, D. Bouzo, P. Brooks, R. Schothauer and E. J. Harry, Therapeutic Manuka Honey: No Longer So Alternative, Front. Microbiol., 2016, 7, 569.

2 V. C. Nolan, J. Harrison and J. A. G. Cox, Dissecting the Antimicrobial Composition of Honey, Antibiotics, 2019, 8(4), 251.

3 A. Girma, W. Seo and R. C. She, Antibacterial activity of varying UMF-graded Manuka honeys, PLoS One, 2019, 14, e0224495.

4 N. N. Cokcetin, M. Pappalardo, L. T. Campbell, P. Brooks, D. A. Carter, S. E. Blair and E. J. Harry, The Antibacterial Activity of Australian Leptospermum Honey Correlates with Methylglyoxal Levels, PLoS One, 2016, 11, e0167780.

5 C. J. Adams, C. H. Boult, B. J. Deadman, J. M. Farr, M. N. Grainger, M. Manley-Harris and M. J. Snow, Isolation by HPLC and characterisation of the bioactive fraction of New Zealand manuka (Leptospermum scoparium) honey, Carbohydr. Res., 2008, 343, 651-659.

6 E. Mavric, S. Wittmann, G. Barth and T. Henle, Identification and quantification of methylglyoxal as the dominant antibacterial constituent of Manuka (Leptospermum scoparium) honeys from New Zealand, Mol. Nutr. Food Res., 2008, 52, 483-489.

7 C. J. Adams, M. Manley-Harris and P. C. Molan, The origin of methylglyoxal in New Zealand manuka (Leptospermum scoparium) honey, Carbohydr. Res., 2009, 344, 1050-1053.

8 S. Williams, J. King, M. Revell, M. Manley-Harris, M. Balks, F. Janusch, M. Kiefer, M. Clearwater, P. Brooks and M. Dawson, Regional, annual, and individual variations in the dihydroxyacetone content of the nectar of manuka (Leptospermum scoparium) in New Zealand, J. Agric. Food Chem., 2014, 62, 10332-10340.

9 A. M. Norton, L. N. McKenzie, P. R. Brooks and L. J. Pappalardo, Quantitation of Dihydroxyacetone in Australian Leptospermum Nectar via High-Performance Liquid Chromatography, J. Agric. Food Chem., 2015, 63, 6513-6517.

10 A. Sindi, M. V. B. Chawn, M. E. Hernandez, K. Green, M. K. Islam, C. Locher and K. Hammer, Anti-biofilm effects and characterisation of the hydrogen peroxide activity of a range of Western Australian honeys compared to Manuka and multifloral honeys, Sci. Rep., 2019, 9, 17666.

11 E. Rabie, J. C. Serem, H. M. Oberholzer, A. R. M. Gaspar and M. J. Bester, How methylglyoxal kills bacteria: An ultrastructural study, Ultrastruct. Pathol., 2016, 40, 107-111.

12 D. I. Godfrey, H. F. Koay, J. McCluskey and N. A. Gherardin, The biology and functional importance of MAIT cells, Nat. Immunol., 2019, 20, 1110-1128.

13 W.-J. Chua, S. M. Truscott, C. S. Eickhoff, A. Blazevic, D. F. Hoft and T. H. Hansen, Polyclonal mucosa-associated invariant $\mathrm{T}$ cells have unique innate functions in bacterial infection, Infect. Immun., 2012, 80, 3256-3267. 
14 M. C. Gold, S. Cerri, S. Smyk-Pearson, M. E. Cansler, T. M. Vogt, J. Delepine, E. Winata, G. M. Swarbrick, W.-J. Chua, Y. Y. L. Yu, O. Lantz, M. S. Cook, M. D. Null, D. B. Jacoby, M. J. Harriff, D. A. Lewinsohn, T. H. Hansen and D. M. Lewinsohn, Human mucosal associated invariant $\mathrm{T}$ cells detect bacterially infected cells, PLoS Biol., 2010, 8, e1000407.

15 L. Kjer-Nielsen, O. Patel, A. J. Corbett, J. Le Nours, B. Meehan, L. Liu, M. Bhati, Z. Chen, L. Kostenko, R. Reantragoon, N. A. Williamson, A. W. Purcell, N. L. Dudek, M. J. McConville, R. A. J. O'Hair, G. N. Khairallah, D. I. Godfrey, D. P. Fairlie, J. Rossjohn and J. McCluskey, MR1 presents microbial vitamin B metabolites to MAIT cells, Nature, 2012, 491, 717-723.

16 L. Le Bourhis, E. Martin, I. Peguillet, A. Guihot, N. Froux, M. Core, E. Levy, M. Dusseaux, V. Meyssonnier, V. Premel, C. Ngo, B. Riteau, L. Duban, D. Robert, S. Huang, M. Rottman, C. Soudais and O. Lantz, Antimicrobial activity of mucosal-associated invariant $\mathrm{T}$ cells, Nat. Immunol., 2010, 11, 701-708.

17 S. Maggio, K. Takeda, F. Stark, A. I. Meierovics, I. Yabe and S. C. Cowley, Control of Francisella tularensis Intracellular Growth by Pulmonary Epithelial Cells, PLoS One, 2015, 10, e0138565.

18 A. J. Corbett, S. B. G. Eckle, R. W. Birkinshaw, L. Liu, O. Patel, J. Mahony, Z. Chen, R. Reantragoon, B. Meehan, H. Cao, N. A. Williamson, R. A. Strugnell, D. Van Sinderen, J. Y. W. Mak, D. P. Fairlie, L. Kjer-Nielsen, J. Rossjohn and J. McCluskey, T-cell activation by transitory neo-antigens derived from distinct microbial pathways, Nature, 2014, 509, 361-365.

19 J. Y. W. Mak, W. Xu, R. C. Reid, A. J. Corbett, B. S. Meehan, H. Wang, Z. Chen, J. Rossjohn, J. McCluskey, L. Liu and D. P. Fairlie, Stabilizing short-lived Schiff base derivatives of 5-aminouracils that activate mucosal-associated invariant T cells, Nat. Commun., 2017, 8, 14599.

20 P. J. O’Brien, A. G. Siraki and N. Shangari, Aldehyde sources, metabolism, molecular toxicity mechanisms, and possible effects on human health, Crit. Rev. Toxicol., 2005, 35, 609-662.

21 H. Wang, C. D’Souza, X. Y. Lim, L. Kostenko, T. J. Pediongco, S. B. G. Eckle, B. S. Meehan, M. Shi, N. Wang, S. Li, L. Liu, J. Y. W. Mak, D. P. Fairlie, Y. Iwakura, J. M. Gunnersen, A. W. Stent, D. I. Godfrey, J. Rossjohn, G. P. Westall, L. Kjer-Nielsen, R. A. Strugnell, J. McCluskey, A. J. Corbett, T. S. C. Hinks and Z. Chen, MAIT cells protect against pulmonary Legionella longbeachae infection, Nat. Commun., 2018, 9, 3350.

22 T. S. C. Hinks, E. Marchi, M. Jabeen, M. Olshansky, A. Kurioka, T. J. Pediongco, B. S. Meehan, L. Kostenko, S. J. Turner, A. J. Corbett, Z. Chen, P. Klenerman and J. McCluskey, Activation and InVivo Evolution of the MAIT Cell Transcriptome in Mice and Humans Reveals Tissue Repair Functionality, Cell Rep., 2019, 28, 3249-3262.
23 J. Lange, R. J. Anderson, A. J. Marshall, S. T. S. Chan, T. S. Bilbrough, O. Gasser, C. Gonzalez-Lopez, M. Salio, V. Cerundolo, I. F. Hermans and G. F. Painter, The Chemical Synthesis, Stability, and Activity of MAIT Cell Prodrug Agonists That Access MR1 in Recycling Endosomes, ACS Chem Biol., 2020, 15, 437-445.

24 M. Pappalardo, L. Pappalardo and P. Brooks, Rapid and Reliable HPLC Method for the Simultaneous Determination of Dihydroxyacetone, Methylglyoxal and 5-Hydroxymethylfurfural in Leptospermum Honeys, PLoS One, 2016, 11(11), e0167006.

25 G. Murayama, A. Chiba, H. Suzuki, A. Nomura, T. Mizuno, T. Kuga, S. Nakamura, H. Amano, S. Hirose, K. Yamaji, Y. Suzuki, N. Tamura and S. Miyake, A Critical Role for Mucosal-Associated Invariant $\mathrm{T}$ Cells as Regulators and Therapeutic Targets in Systemic Lupus Erythematosus, Front. Immunol., 2019, 10, 2681.

26 M. Salio, O. Gasser, C. Gonzalez-Lopez, A. Martens, N. Veerapen, U. Gileadi, J. G. Verter, G. Napolitani, R. Anderson, G. Painter, G. S. Besra, I. F. Hermans and V. Cerundolo, Activation of Human Mucosal-Associated Invariant T Cells Induces CD40L-Dependent Maturation of Monocyte-Derived and Primary Dendritic Cells, J. Immunol., 2017, 199, 2631-2638.

27 M. Wolfl, J. Kuball, W. Y. Ho, H. Nguyen, T. J. Manley, M. Bleakley and P. D. Greenberg, Activation-induced expression of CD137 permits detection, isolation, and expansion of the full repertoire of $\mathrm{CD} 8(+) \mathrm{T}$ cells responding to antigen without requiring knowledge of epitope specificities, Blood, 2007, 110, 201-210.

28 L. Ghazarian, S. Caillat-Zucman and V. Houdouin, Mucosal-Associated Invariant $\mathrm{T}$ Cell Interactions with Commensal and Pathogenic Bacteria: Potential Role in Antimicrobial Immunity in the Child, Front. Immunol., 2017, 8, 1837.

29 A. N. Keller, S. B. G. Eckle, W. Xu, L. Liu, V. A. Hughes, J. Y. W. Mak, B. S. Meehan, T. Pediongco, R. W. Birkinshaw, Z. Chen, H. Wang, C. D'Souza, L. KjerNielsen, N. A. Gherardin, D. I. Godfrey, L. Kostenko, A. J. Corbett, A. W. Purcell, D. P. Fairlie, J. McCluskey and J. Rossjohn, Drugs and drug-like molecules can modulate the function of mucosal-associated invariant T cells, Nat. Immunol., 2017, 18, 402-411.

30 F. Legoux, D. Bellet, C. Daviaud, Y. El Morr, A. Darbois, K. Niort, E. Procopio, M. Salou, J. Gilet, B. Ryffel, A. Balvay, A. Foussier, M. Sarkis, A. El Marjou, F. Schmidt, S. Rabot and O. Lantz, Microbial metabolites control the thymic development of mucosal-associated invariant $\mathrm{T}$ cells, Science, 2019, 366, 494-499.

31 I. Hama, K. Tominaga, S. Yamagiwa, T. Setsu, N. Kimura, H. Kamimura, T. Wakai and S. Terai, Different distribution of mucosal-associated invariant $\mathrm{T}$ cells within the human cecum and colon, Cent. Eur. J. Immunol., 2019, 44, 75-83. 